\title{
Community Driven Development Dalam I mplementasi Corporate Social Responsibility oleh PT. Pertamina Subang
}

\author{
Risna Resnawaty ${ }^{1}$ Rudi Saprudin Darwis² \\ 1. Program Studi Kesejahteraan Sosial, Fakultas IImu Sosial Dan IImu Politik, Universitas \\ Padjadjaran \\ risna.resnawaty@unpad.ac.id \\ 2. Program Studi Kesejahteraan Sosial, Fakultas IImu Sosial Dan IImu Politik, Universitas \\ Padjadjaran \\ rsdarwis@gmail.com
}

\begin{abstract}
ABSTRAK
Implementasi CSR oleh badan usaha milik negara sering dianggap sebagai program bantuan sukarela. Tapi tidak demikian dengan program CSR yang dilakukan oleh PT. Pertamina field Subang. Program CSR pada awalnya lebih didominasi oleh program insidental yang berangsur-angsur bergerak menuju pemberdayaan masyarakat. Program pengelolaan sampah menjadi salah satu andalan dalam pelaksanaan CSR di Dusun Dangdeur Kabupaten Subang yang berupaya untuk memberdayakan masyarakat.

Community Driven Development (CDD) adalah sebuah konsep yang dapat menjelaskan upaya dan inisiatif masyarakat dalam melaksanakan pengembangan masyarakat. Program CDD sebagai implementasi CSR ini diinisiasi oleh perusahaan, kemudian perusahaan melibatkan dan melatih masyarakat agar bisa mengendalikan proses pengembangan masyarakat secara mandiri, melalui penggunaan aset sumber daya dan membuat keputusan pengambilan wewenang langsung dalam menentukan keberlangsungan program dan pencapaian tujuan bersama dalam masyarakat tersebut. Keywords: community development, community Driven Development, CSR.
\end{abstract}

\begin{abstract}
The implementation of CSR by state-owned enterprises is often considered a voluntary aid program. In this case, CSR program conducted by PT. Pertamina field Subang. Pertamina Subang creating Rumah Inspirasi as the major CSR Program. The CSR program was initially dominated by incidental programs which gradually moved towards community empowerment. The waste management program is one of the mainstays in the implementation of CSR in Dangdeur Hamlet, Subang Regency, which seeks to empower the community.

Community Driven Development (CDD) is a concept that can explain community efforts and initiatives in carrying out community development. The CDD program as a CSR implementation is initiated by the company, then the company engages and trains the community to be able to control the community development process independently, through the use of resource assets and make direct decisionmaking decisions in determining the sustainability of the program and achieving common goals in the community.
\end{abstract}

Keywords: community development, community Driven Development, CSR. 


\section{PENDAHULUAN}

Tanggung jawab sosial dan lingkungan yang dikenal dengan istilah Corporate Social Responsibility (CSR) sudah merupakan istilah asing bagi perusahaan maupun bagi masyarakat sekitar. Keberadaan perusahaan di tengah masyarakat menuntut adanya kepedulian dari perusahaan terhadap kondisi sosial dan lingkungan. Hal ini tidak dapat dielakkan, mengingat terjadi kesenjangan yang nyata terutama kondisi masyarakat sekitar yang masih belum memiliki kualitas hidup yang baik sementara perusahaan melakukan ekplorasi dan eksploitasi sumber daya alam dengan teknologi canggih. Kesenjangan ini menimbulkan kecemburuan sosial dari masyarakat yang memerlukan sebuah bentuk kepedulian dari perusahaan, sehingga perusahaan dapat mencapai target operasinya secara maksimal, sementara masyarakat dapat meningkat kualitas hidupnya melalui program CSR yang diinisiasi oleh perusahaan.

Resnawaty (2015); Rahmatullah (2011); menyebutkan bahwa Indonesia telah melek CSR sejak tahun 1980an ketika itu perusahaan milik Negara wajib melaksanakan program kemitraan "Bapak-angkat" atau yang difahami sebagai kegiatan pemberdayaan ekonomi yang memiliki fokus pada bantuan permodalan bagi usaha kecil. Perusahaan Negara berperan sebagai bapak, sementara masyarakat berperan sebagai anak. Dengan syarat masyarakat yang memiliki usaha kecil boleh mengajukan permohonan untuk dibantu modal usahanya. Pada dekade 1990an kegiatan CSR ini mulai marak dilakukan perusahaan milik Negara dikenal dengan Program Kemitraan dan Bina Lingkungan, sementara perusahaan swasta sudah mulai melaksanakan program CSR melalui bantuan-bantuan sosial bagi lingkungan sekitar. Pada era tahun 2000, pelaksanaan CSR ramai dengan program pengembangan masyarakat, seiring dengan undang-undang tambang mineral dan batu bara maupun undang-undang migas, serta lahirnya undang-undang Perseroan Terbatas yang membahas mengenai tanggung jawab sosial dan lingkungan. Program pengembangan masyarakat yang dikenal dengan program community development dimaknai sebagai program pembangunan infrastruktur dan pembangunan sarana dan prasarana dalam kehidupan masyarakat. padahal gagasan dari pengembangan masyarakat atau community development sendiri adalah sebuah aktivitas yang berupaya untuk meningkatkan kualitas hidup masyarakat melalui sebesar-besarnya partisipasi masyarakat (Adi 2002, Ife 1995, Cary 1970, PBB 1948 dalam Adi 2003)

Berbagai program CSR yang diimplementasikan oleh perusahaan menuai beberapa permasalahan, pengetahuan masyarakat mengenai kewajiban perusahaan melakukan CSR menyebabkan benih-benih ketergantungan dari masyarakat terhadap perusahaan. Masyarakat menganggap bahwa perusahaan wajib memenuhi seluruh kebutuhan masyarakat, sementara di lain pihak perusahaan memiliki motif mencapai keuntungan secara maksimal dari upaya yang telah mereka lakukan.

\section{Community}

Driven Development (CDD) dikenal pada awal tahun 2010, CDD ini merupakan sebuah pendekatan dalam pelaksanaan pembangunan dengan meningkatkan inisiatif masyarakat untuk berperan aktif sebagai pelaku atau pengelola (Dasgupta, 2007). Di mana masyarakat yang pada awalnya hanya menjadi 
sasaran dari sebuah perubahan digiring untuk menjadi pelaksana dari keseluruhan proses pengembangan masyarakat.

Dongier (2002) menyatakan bahwa CDD dapat dilakukan melalui upaya memperkuat dan memberikan pendanaan bagi kelompok masyarakat, memfasilitasi akses masyarakat terhadap informasi, meningkatkan kualitas lingkungan masyarakat yang gilakukan melalui reformasi kebijakan dan kelembagaan. Dongier menekankan pada adanya kelompok kerja dalam masyarakat yang menjadi motor penggerak aktivitas yang dilakukan. Dalam CDD ini diharapkan adanya sebuah kelembagaan baru yang disepakati bersama yang menjadi aturan bagi masyarakat dalam mewujudkan tujuan bersama.

CDD dalam implementasi CSR bukan hal yang utopia, sebab telah terjadi pergeseran dari yang semula CSR bersifat charity menjadi ke arah pemberdayaan. CDD ini dapat menjadi salah satu alternative yang dapat dilakukan sebagai upaya pemberdayaan masyarakat. Pada era Sustainable Development Goals (SDGs) ini, perusahaan yang juga menjadi salah satu pelaku pembangunan harus ikut membantu dalam pencapaian target pembangunan global.

Yang menjadi kekhawatiran adalah adalah apakah masyarakat mampu untuk menjadi mandiri paska tambang? Tentu hal ini yang perlu disiapkan oleh perusahaan sebagai pelaku utama dalam CSR. Penelitian BPMIGAS (2009; 2010), Resnawaty (2015) mengemukakan fakta bahwa masyarakat bisa dilatih untuk menjadi mandiri apabila dilakukan sebuah metode pelibatan masyarakat dalam keseluruhan proses. Hal ini menjadi sangat penting terkait dengan keberdayaan dan kemandirian masyarakat di masa yang akan datang setelah perusahaan tidak lagi beroperasi.

PT. Pertamina Subang memiliki sebuah program CSR yang bernama Green House yang berfokus pada program bank Sampah masyarakat dan sanggar inspirasi untuk meningkatkan kualitas hidup dan mewujudkan mimpi masyarakat. program ini diinisasi oleh perusahaan melalui community development office/Staf CSR perusahaan. Program ini memiliki tujuan untuk memberdayakan masyarakat dengan pola memberikan pemicuan pada masyarakat berupa program kemudian mendorong agar masyarakat mampu untuk menjalankan program ini secara mandiri dan berkelanjutan. Program Green House ini memiliki ruh yang sama dengan CDD, dengan program CSR yang memiliki muatan CDD menjadi sangat penting untuk dianalisis sehingga akan memberikan referensi baru bagi pelaksanaan CSR di Indonesia.

\section{Community Driven Development: sebuah pendekatan terencana dalam mengembangkan kapasitas masyarakat}

\section{Community driven development (CDD)} merupakan sebuah program yang dirancang untuk menghimpun inisiatif dan partisipasi masyarakat. Tanaka (2006) menyebutkan bahwa CDD ini merupakan pengembangan dari Community Based Development (CBD). Jika CBD memfokuskan pada berbagai cara dan tindakan berbasis masyarakat dalam proses program dengan penekanan pada cara-cara dan sumber daya lokal yang dimiliki masyarakat. Maka CDD ini merupakan upaya-upaya terorganisir dengan pola pembangunan yang mencakup aktivitas yang lebih luas yang lebih luas. Sebagai contoh, proyek-proyek CBD dapat mencakup semuanya, mulai dari 
berbagi informasi sederhana hingga pemberdayaan sosial, ekonomi, dan politik kelompok masyarakat.

CDD memiliki karakter yang sesuai dengan tujuan pemberdayaan, karakteristik utama dalam CDD selain secara aktif melibatkan masyarakat dalam merencanakan, manajemen, dan melakasanakan proyek. CDD memiliki penekanan pada pada pengambilan keputusan dan pengelolaan sumber daya kegiatan di hampir semua tahap program.

Terdapat 5 (lima) karakteristik utama dalam CDD yang akan memberikan penjelasan bagaimana kedudukan masyarakat dalam sebuah program, serta langkah-langkah yang dilakukan untuk membangun keterlibatan penuh dari masyarakat sehingga mereka memiliki keterampilan dalam mengelola kegiatan pembangunan secara mandiri.

Intinya, kelima karakter CDD ini sesungguhnya merupakan langkah perbaikan dari kegiatan CBD. Namun demikian, fokus pada kekuatan yang ada pada komunitas menjadi persamaan antara CDD dan CBD. Sedangkan selebihnya terdapat perbedaan antara lain CDD memberikan kesempatan pada masyarakat untuk mengelola program secara mandiri dan terstruktur. Terdapat lima karakteristik utama proyek CDD menurut Word Bank (2011):

1. Pelaksanaan CDD berupaya melibatkan organisasi berbasis komunitas atau kelembagaan dan perwakilan dari masyarakat yang dianggap paling mengetahui kondisi dalam masyarakat di sana. Fokus terhadap komunitas ini memiliki arti bahwa karakteristik penting dari proyek CDD adalah penerima manfaat atau penerima hibah dari implementasi adalah agen masyarakat.

2. kegiatan CDD, melalui organisasi berbasis masyarakat yang dimemiliki berbasis masyarakat atau lokal bertanggung jawab untuk merancang dan merencanakan subproyek secara partisipatif.

3. Karakteristik utama proyek CDD adalah bahwa sebagai sebuah upaya pemberdayaan, program CDD melatih masyarakat agar mampu melakukan akses, pengendaliaan dan pengelolaan sumber daya. Dalam hal ini masyarakat diberikan wewenang untuk mengelola program sesuai dengan kebutuhan dan tujuan yang akan tercapai.

4. Masyarakat terlibat langsung dalam pelaksanaan subproyek. Seringkali partisipasi masyarakat datang langsung dalam bentuk tenaga kerja atau dana. Namun demikian, masyarakat juga dapat berkontribusi pada subproyek secara tidak langsung dalam bentuk manajemen dan pengawasan kontraktor atau operasi dan pemeliharaan infrastruktur ketika selesai.

5. Unsur pemantauan dan evaluasi berbasis masyarakat telah menjadi karakteristik subproyek CDD. Paling sering dilakukan adalah alat akuntabilitas sosial seperti pemantauan partisipatif, kartu penilaian masyarakat dan sistem penanganan keluhan yang memungkinkan masyarakat untuk memastikan akuntabilitas penerapan CDD.

Dalam konteks CSR, Undangundang Migas No. 22 Tahun 2001 
menyebutkan bahwa setiap perusahaan yang melakukan ekstraksi migas harus melaksanaan pengembangan dan pemberdayaan masyarakat yang berada di lingkungan sekitarnya, serta memberikan perlindungan terhadap hak-hak adat. Jika pada Undangundang tersebut community development muncul sebagai sebuah kewajiban, maka pelaksanaan CDD pada masa sekarang menjadi sebuah implementasi dalam pelaksanaan tanggung jawab sosial dari perusahaan. Sebab pelaksanaan CSR pada masa lalu dapat menimbulkan ketergantungan dari masyarakat terhadap perusahaan.

\section{METODE}

Penelitian yang dilakukan untuk menghimpun data mengenai Community Driven Development dalam CSR ini adalah penelitian kualitatif dengan metode deskriptif. Kurun waktu penelitian adalah selama 8 bulan di mulai pada bulan April 2017 sampai dengan bulan Desember 2017. Jumlah informan adalah sebanyak 17 orang yang terdiri dari Pelaksana CSR PT. Pertamina Subang, Pemerintah Kecamatan dan kabupaten Subang, masyarakat dusun Dangdeur, serta penerima manfaat program CSR PT. Pertamina Subang.

\section{Rumah Inspirasi: Program CSR Kepedulian terhadap Kualitas Hidup dan Kualitas Lingkungan}

\section{Program CSR Pertamina EP Asset 3} Subang Field mengusung konsep Ecogreen yaitu peningkatan kualitas hidup manusia dengan tema kepedulian terhadap lingkungan. Ecogreen merupakan sebuah konsep yang berangkat dari filosofi ekologi, sosial, dan ekonomi di mana program CSR ini berupaya mengajak masyarakat untuk mengintegrasikan kelestarian lingkungan sosial dengan cara hidup berdampak rendah pada lingkungan. Hal ini merupakan penyelarasan antara visi dan misi perusahaan dalam menjalankan bisnis yang kemudian ditularkan dalam aktivitas CSRnya. Sehingga kepedulian terhadap lingkungan bukan hanya dalam pelaksanaan eksplorasi dan eksploitasi migas, namun pada serangkaian program CSR, sehingga menjaga kelestarian lingkungan dapat mengakar dan membudaya pada diri masyarakat.

Kepedulian terhadap lingkungan dan kondisi sosial ekonomi masyarakat mendorong pimpinan Pertamina Subang untuk melakukan pemberdayaan untuk pemerataan kesejahteraan di sekitar lokasi. Pertamina EP Asset 3 Subang Field mengiimplementasikannya CSRnya melalui Rumah Inspirasi. Rumah Inspirasi ini memiliki tujuan untuk peningkatan kualitas hidup dan kesejahteraan masyarakat ring 1 dari sumur galian Pertamina.

Rumah Inspirasi, meskipun memiliki kata "Rumah" pada dasarnya bukan menunjukkan pada suatu tempat. Namun menunjukkan pada suatu lembaga atau institusi lokal yang dibentuk dan dijalankan oleh masyarakat Kelurahan Dangdeur untuk mencapai suatu kondisi yang dicitacitakan masyarakat. Program Rumah Insrirasi ini disusun oleh CDO dari Pertamina EP Asset 3 Subang Field dan berupaya menghimpun masyarakat untuk menjadi penggerak utama. Rumah Inspirasi sendiri terdiri dari dua aktivitas yaitu Bank sampah (Broery) dan sanggar Inspirasi (SARI). Pertamina EP Asset 3 Subang Field memberikan bantuan sarana dan prasarana di RW 10 serta pendampingan program oleh CDO. Rumah inspirasi ini diharapkan menjadi "Rumah" tempat warga masyarakat melakukan aktivitas secara bersama- 
sama untuk memperbaiki kualitas hidupnya; peningkatan pendapatan, peningkatan kebersihan lingkungan, dan peningkatan keterampilan.

\section{Daur Program Terpenting dalam CDD sebagai Implementasi CSR}

Upaya membangun kemampuan dari masyarakat untuk melaksanakan program dalam implementasi CSR Pertamina Subang ini terbagi atas dua hal penting: Pelibatan stakeholder dan perencanaan yang matang, serta kesempatan untuk berpartisipasi.

\section{HASIL DAN PEMBAHASAN}

\section{a. Pelibatan Stakeholder dan Perencanaan yang matang}

Proses perencanaan program diawali oleh inisiatif CDO yang mengajukan proposal program baru kepada pimpinan perusahaan, untuk membangun sebuah program yang benar-benar masyarakat diperlukan dukungan yang kuat dari CEO. Dalam tahapan perencanaan ini masyarakat dan pemerintah tidak dilibatkan untuk penyusunan program Rumah Inspirasi. Dalam perencanaan awal pihak perusahaan sangat mengandalkan hasil dari pemetaan sosial yang telah dilakukan pada tahun sebelumnya yaitu 2015.

Sasaran dari program Rumah Inspirasi adalah kelompok pemuda marjinal (pengangguran, putus sekolah, pemakai narkoba) serta ibu-ibu rumah tanggga yang tidak bekerja yang berada di Kelurahan Dangdeur khususnya dan seluruh masyarakat Kabupaten Subang pada umumnya. Penerima manfaat dari program Rumah Inspirasi pun tidak hanya sekitar ring 1 program yaitu di Kelurahan Dangdeur melainkan sampai kepada seluruh masyarakat di Kabupaten Subang.

Program Rumah Inspirasi disusun melalui rencana kerja selama 5 tahun dengan tujuan akhirnya menjadikan Rumah Inspirasi menjadi mandiri. Pada tahun 2015 Rumah Inspirasi menyiapkan perencanaan program, sosialisasi ke stakeholder terkait dan pembentukan kelompok dampingan. Langkah yang ditempuh mengacu pada karakteristik CDD yaitu pengembangan melalui organisasi lokal (World Bank, 2002). Di tahun 2016, CDO melakukan penguatan kelompok dengan menyiapkan kapsitas sumber daya manusia agar mampu megelola organisasi serta memiliki kemampuan dalam pengelolaan bahan bakar alternatif. Pada tahun ini pula Pertamina EP Asset 3 Subang Field menyiapkan kebutuhan sarana dan prasarana untuk kegiatan Rumah Inspirasi. Tahun 2017, Rumah Inspirasi mulai mengembangkan organisasinya dengan perluasan kerjasama dengan berbagai elemen serta perluasan nasabah yang menjangkau kelurahan lain di Kecamatan Subang dan beberapa lembaga seperti sekolah dan dinas pemerintahan. Tahun 2018, Rumah Inspirasi bisa menghasilkan inovasi produk hasil Bank Sampah. Tahun 2019, Rumah Inspirasi bisa mencapai kemandirian dan keberlanjutan dalam pengelolaan sampah dan sanggar inspirasi. pada tahun ini pula Rumah Inspirasi diharapkan bisa menjadi mitra kerja dari Pertamina EP Asset 3 Subang Field tidak lagi menjadi program dampingan perusahaan.

Pada proses awal terbentuknya Rumah Inspirasi Community Development Officer (CDO ) sebagai pelaksana kegiatan Corporate Social Responbility Pertamina EP Asset 3 Subang Field melakukan sosialisasi kepada para stakeholder yang berpengaruh di Kelurahan Dangdeur yang bertujuan untuk mengiformasikan program serta mencari dukungan dari Stakeholder terkait. Informasi 


\begin{tabular}{|c|c|c|c|c|}
\hline Share: Social Work Jurnal & VOLUME: 8 & NOMOR: 1 & HALAMAN: 64-73 & $\begin{array}{c}\text { ISSN:2339 -0042 (p) } \\
\text { ISSN: 2528-1577 (e) } \\
\text { Doi: 10.24198/share.v8i1.16426 }\end{array}$ \\
\hline
\end{tabular}

mengenai aktivitas program disebarluaskan sampai keseluruh lapisan masyarakat diharapkan masyarakat akan tertarik untuk bergabung menjadi pengurus dan nasabah program bank sampah. Sosialisasi ini menghasilkan sebuah bentuk kepengurusan mandiri dari masyarakat, serta munculnya kepemimpinan local yang menjadi motor penggerak.

Pelaksanaan Program Rumah Inspirasi bukan tidak mengalami hambatan, pada awalnya bangunan yang disepakati sebagai tempat pengelolaan sampah dinilai tidak lagi representatif. Rumah Inspirasi memerlukan lahan yang luas untuk aktivitas kedua programnya. Oleh sebab itu pengurus beserta CDO dan pemerintah kelurahan bermusyawarah untuk memindahkan lokasi program Rumah Inspirasi ke lokasi yag lebih luas. Alternatif pemecahan masalah lahir dari stakeholder yaitu masyarakat dan pemerintah kelurahan, sedangkan CDO berperan sebagai fasilitatior. Pada akhirnya disepakati oleh pengurus Rumah Inspirasi bahwa pemindahan lokasi akan dilakukan pada tanah milik pimpinan Rumah Inspirasi untuk kepentingan dan keberlanjutan program.

Namun permasalahan lain muncul, tidak semua puas dalam solusi yang diterapkan. Pihak pemerintah tidak merasa dilibatkan dan tidak mengetahui keputusan akhir mengenai pemindahan lahan. Hal tersebut dipertanyakan pihak pemerintah karena setelah diskusi tentang ijin penggunaan lahan di Kelurahan Dangdeur, pihak CDO tidak lagi menghubungi pemerintah perihal lokasi akhir pembangunan Rumah Inspirasi. Polemik ini menjadi berkepanjangan, meskipun Rumah Inspirasi tetap berjalan, namun dukungan dari pemerintah menjadi berkurang.
Masalah lain terjadi pemindahan lokasi Rumah Inspirasi menimbulkan kekecewaan dari beberapa pengurus yang berasal dari lokasi sebelumnya, kepindahan ini menyebabkan rasa memiliki terhadap program menjadi berkurang. Hal tersebut menyebabkan mundurnya beberapa pengurus dari Rumah Inspirasi yang berasal dari lokasi sebelumnya.

Tiga karakteristik dari CDD dapat dipenuhi pada program Rumah Inspirasi ini, yaitu pelibatan dari organisasi lokal, partisipasi dalam design program, serta pemanfaatan sumberdaya yang ada. Dalam hal ini masyarakat sebagai pengurus dari program telah memiliki inisiatif untuk pemecahan masalah, namun sosialisasi dalam setiap perubahan tidak dilakukan dengan baik. Sehingga Rumah Inspirasi mengalami dinamika sejak awal berdiri. Berkurangnya dukungan dari anggota dan stakeholder lain yaitu pemerintah menyebabkan fokus pencapaian tujuan terganggu sejak awal.

\section{b. Kesempatan Masyarakat untuk Berpartisipasi}

CDD mensyaratkan adanya sebuah kelembagaan lokal yang terlibat penuh dalam keseluruhan aktivitas program. Masyarakat menjadi pemilik, pelaksana, sekaligus penanggungjawab program. Pendekatan yang dilakukan oleh CDO Pertamina Subang adalah melalui pendekatan institusi lokal, Rumah Inspirasi merupakan kelembagaan lokal yang dibentuk oleh masyarakat untuk kepentingan pelaksanaan CSR, terdiri atas tokoh-tokoh masyarakat, dan anggota masyarakat yang memiliki keinginan untuk meningkatkan kualitas hidup baik bagi dirinya pribadi maupun bagi masyarakat kelurahan Dangdeur secara keseluruhan. 
Kapasitas pengetahuan dan kemampuan dari pengurus ditingkatkan melalui pelatihan-pelatihan atas suppport dari CDO selaku pelaksana program CSR. CDO memberikan kesempatan pada masyarakat untuk merencanakan kegiatan yang sesuai dengan minat dan kebutuhan mereka. Sanggar Inspirasi (SARI) sebagai salah satu unit kegiatan di Rumah Inspirasi mewadahi kegiatan-kegiatan yang bersifat substansial dengan transfer knowledge kepada masyarakat: seperti meningkatkan kemampuan berbahasa Inggris, melestarikan nilai budaya Sunda, taman bacaan, serta bengkel kreatif. Sanggar inspirasi ini berfokus pada peningkatan pengetahuan dan keterampilan warga. Dari keseluruhan program, yang dapat berjalan secara maksimal adalah Bengkel Kreatif sebab memiliki nilai tambah pada pendapatan warga, sedangkan kegiatan yang bersifat edukasi tidak berkelanjutan jika support dari Perusahaan berkurang.

Program Rumah Inspirasi yang terkait dengan lingkungan adalah Bank Roentah Inspirasi (Broery). Inilah program utama atau unggulan yang bertujuan menyelesaikan permasalahan lingkungan dengan mengedukasi masyarakat agar bisa mengelola sampah. Masyarakat dilibatkan sebagai nasabah yang menabung sampah ke Broery dengan mendapatkan bayaran dari hasil tabungannya tersebut. Tabungan sampah tersebut bisa diambil setelah 3 bulan menabung.

Program pengelolaan sampah ini melibatkan masyarakat secara umum, mereka yang melihat program ini sebagai potensi ekonomi langsung tertarik untuk terlibat. Rumah Inspirasi bekerjasama dengan pengepul tersebut dengan tujuan agar tidak terjadi persaingan antara Broery dengan Pengepul sampah lokal. Rumah Inspirasi diharapkan mampu bekerjasama dan memberi nilai manfaat bagi masyarakat secara lebih luas. Dalam hal ini karakteristik CDD yang keempat mengenai keterlibatan dalam subproyek terpenuhi, meskipun pada kenyataannya anggota dari program ini tidak bertambah malah cenderung berkurang. Program Bank Sampah bisa memberikan peningkatan pendapatan bagi yang betul-betul mengerti dan memiliki modal.

Monitoring dan Evaluasi adalah tahap yang dianggap sebagai umpan balik yang dapat memberi masukan demi perbaikan pelaksanaan program selanjutnya. Setiap Stakeholder memiliki peran penting dalam tahap evaluasi, mengingat posisi masyarakat, Perusahaan dan Pemerintah pada suatu program pengembangan adalah sebagai subyek yang sama sama terlibat dalam pelaksanaan program.

Monitoring dan evaluasi merupakan serangkaian kegiatan yang dilakukan oleh Pertamina EP Asset 3 Subang Field bersama CDO dalam mendampingi Rumah Inspirasi. Monitoring dan evaluasi di tingkat organisasi dilakukan oleh CDO. CDO yang ditunjuk sebagai penanggung jawab Rumah Inspirasi setiap hari datang kelokasi dampingan untuk melihat kegiatan dan perkembangan dari Rumah Inspirasi.

Evaluasi internal juga dilakukan oleh Rumah Inspirasi sebagai sebuah organisasi. Evaluasi ini dilakukan pada hari selasa setiap minggunya dengan melibatkan semua pengurus Rumah Inspirasi dari Manager, asissten manager, Anggota dan CDO sebagai pendamping. Dalam kegiatan ini, berbagai hal dimusyawarahkan seperti masalah dan hambatan dalam kegiatan, rencana kegiatan yang akan dilakukan, serta perluasan kerjasama dengan stakeholder terkait.

Monitoring dan evaluasi juga dilakukan oleh Pertamina EP Asset 3 Subang Field dengan datang langsung 


\begin{tabular}{|l|l|l|l|l|}
\hline Share: Social Work Jurnal & VOLUME: 8 & NOMOR: 1 & HALAMAN: 64-73 & $\begin{array}{l}\text { ISSN:2339 -0042 (p) } \\
\text { ISSN: 2528-1577 (e) } \\
\text { Doi: 10.24198/share.v8i1.16426 }\end{array}$ \\
\hline
\end{tabular}

ke Rumah Inspirasi. Perusahaan melakukan monitoring dan evaluasi sebulan sekali tergantung kepentingan dan kebutuhan perusahaan. Perusahaan dalam hal ini adalah manager dari atasan dari CDO sebagai pelaksana serta manager field Pertamina EP Asset 3 Subang. Monitoring dan evaluasi juga dilakukan kepada CDO sebagai pelaksana program. Hal tersebut untuk melihat performa dari CDO dalam pengembangan pemberdayaan program. Dalam hal ini masyarakat belum terlibat dalam monitoring dan evaluasi. Masyarakat belum diajak duduk bersama melihat situasi dan perubahan yang mereka lalui dari waktu ke waktu. Hal ini juga yang menyebabkan program Broery pada saat penelitian ini dilakukan, jumlah anggota yang aktif lebih sedikit dibandingkan dengan pada saat didirikan. Sebab masyarakat tidak merasa secara utuh memiliki program ini. Masyarakat masih merasa perusahaan memiliki tanggung jawab yang paling besar untuk keberlangsungan program Rumah Inspirasi.

\section{KESIMPULAN}

Tiga kriteria awal dari community development driven yaitu pelibatan organisasi lokal, pelibatan masyarakat dalam pembuatan design program serta pemanfaatan sistem sumber lokal pada awalnya dapat tercapai dengan baik, namun kemudian mengalami hambatan karena kurangnya koordinasi antar stakeholder. Dukungan dari pemerintah, masyarakat secara umum, serta dari perusahaan pelaksana CSR akan mendorong program berjalan secara lebih stabil.

Keterlibatan dari seluruh stakeholder menjadi kunci keberhasilan dari community development driven dalam implementasi CSR. keterlibatan ini dapat dicapai melalui koordinasi pada setiap perubahan yang terjadi. Program Rumah Inspirasi yang dilakukan oleh PT. Pertamina pada awalnya berhasil dengan baik dan dapat merangkul masyarakat untuk terlibat dalam program. Ketika dinamika dalam program terjadi, maka koordinasi perlu terus dilakukan secara menyeluruh. Rumah Inspirasi sebagai wadah berkumpulnya masyarakat perlu mendapatkan penguatan dari stakeholder lain sebagai sistem sumber ketika permasalahan terjadi.

Community development driven memiliki tujuan agar masyarakat mampu mengelola program secara mandiri, kesempatan yang diberikan bagi masyarakat untuk berpartisipasi melatih masyarakat untuk menjawab tantangan dari permasalahan yang datang.

\section{DAFTAR PUSTAKA}

Adi, Isbandi Rukminto. (2002). Pemikiranpemikiran dalam pembangunan kesejahteraan sosial. Jakarta: Lembaga Penerbit FE UI.

Andrew Kakabadse, N. K. (2007). CSR in Practice. New York: Palgrave Macmillan.

Babbie, A. R. (2005). Research Methods for Social Work. Belmont: Thomson Brooks/Cole.

Beder, S. (1993). The Nature of Sustainable Development. Newham Vic: Scribe Publication.

BP Migas, 2009, Studi Pelaksanaan Community Development Pasca CSR tidak termasuk dalam Cost Recovery.
Cary,
L.J.
1970.
Community
Development As a Process. 


\begin{tabular}{|c|c|c|c|c|}
\hline Share: Social Work Jurnal & VOLUME: 8 & NOMOR: 1 & HALAMAN: 64-73 & $\begin{array}{l}\text { ISSN:2339-0042 (p) } \\
\text { ISSN: 2528-1577 }(e) \\
\text { Doi: 10.24198/share.v8i1.16426 }\end{array}$ \\
\hline
\end{tabular}

Columbia: University of Missouri

Press

Dasgupta, A., and V.A. Beard (2007) Community Driven

Development, Collective Action and Elite Capture in Indonesia. Development and Chance 38(2), 229-249.

Dongier, P. and Van Domelen, J., Ostrom, E., Ryan, A., Wakeman, W. Bebbington, A. Alkire, S. Esmail, T., \& Polski, M. (2002), "Community Driven Development” in: Klugman, J. (ed), Sourcebook for Poverty Reduction Strategies, Washington DC.: World Bank.

Eweje, G. (2006). The Role of MNE'sin Community Development Initiatives in Developing Countries. Sage Publication volume 45, 93-129.

Frynas, J. G. (2009). Beyond orporate Soial Responsibility. New York: Cambridge University Press.

Griffin, A. (2008). Reputation Management "Gaining Control of Issues, Crises and CSR. London: Kogan Page.

Hopkins, M. (2007). Corporate Social Responsibility \& International Development; Is Business The Solution? United Kingdom: Earthscan.

Ife, J. 1995. Community Development: Creating Community Alternatives - Vision, Analysis and Practice. Melbourne: Longman.

Idemudia, U. (2009). Oil Extraction and Poverty Reduction in Niger Delta: A Critical Examination of Partnership Initiatives. Business Ethics, 90/91-116.
Magness, V. (2008). Who are Stakeholders Now; An Empirical Examination of The Mitchell, Agel, and Wood Theory of Stakeholder Salience. Journal of Business Ethics No. 83, 177-192.

Neuman, L. (2000). Social research Methods (Qualitative and Quantitative Approaches). Boston: Allyn and Bacon.

Rudito, B., Budimanta, A., \& Prasetijo, A. (2004). Corporate Social Responsibility: Jawaban BAgi Model Pembangunan Indonesia Masa Kini. Jakarta: Indonesia Center for Sustainable Development (ICSD).

Rahmatullah dan Trianita, K. (2011).

Panduan Praktis Pengelolaan CSR. Samudra Biru: Yogyakarta.

Resnawaty, Risna, (2015), CSR Perusahaan Tambang, Bandung: Unpad Press

Tanaka (2006). Supporting Community-Driven

Development in Developing Member Countries, Asian Development Bank Report.

Wong, Susan and Scott Guggenheim. (2002). Community-Driven Development: Decentralization's Accountability Challenge, World Bank Report

World Bank (2011a), Measuring Impact of Community- Driven Development Projects on Gender- Toolkit for the Poverty Reduction Fund, Lao PDR, Washington, DC: World Bank 